\title{
The Muscarinic Acetylcholine Receptor Agonist BuTAC Mediates Antipsychotic-Like Effects via the M4 Subtype
}

\author{
Marla L Watt', Linda Rorick-Kehn', David B Shaw', Karen M Knitowski', Anne T Quets', \\ Amy K Chesterfield', David L McKinzie' and Christian C Felder*,I \\ 'Lilly Research Laboratories, Eli Lilly, Lilly Corporate Center, Indianapolis, IN, USA
}

\begin{abstract}
The generation of muscarinic acetylcholine receptor (mAChR) subtype-selective compounds has been challenging, requiring use of nonpharmacological approaches, such as genetically engineered animals, to deepen our understanding of the potential that members of the muscarinic receptor subtype family hold as therapeutic drug targets. The muscarinic receptor agonist 'BuTAC' was previously shown to exhibit efficacy in animal models of psychosis, although the particular receptor subtype(s) responsible for such activity was unclear. Here, we evaluate the in vitro functional agonist and antagonist activity of BuTAC using an assay that provides a direct measure of G protein activation. In addition, we employ the conditioned avoidance response paradigm, an in vivo model predictive of antipsychotic activity, and mouse genetic deletion models to investigate which presynaptic mAChR subtype mediates the antipsychotic-like effects of BUTAC. Our results show that, in vitro, BuTAC acts as a full agonist at the M2AChR and a partial agonist at the MI and M4 receptors, with full antagonist activity at M3- and M5AChRs. In the mouse conditioned avoidance response (CAR) assay, BuTAC exhibits an atypical antipsychotic-like profile by selectively decreasing avoidance responses at doses that do not induce escape failures. CAR results using $\mathrm{M}^{-1-}, \mathrm{M}^{-1-}$, and $\mathrm{M} 2 / \mathrm{M} 4\left(\mathrm{M} 2 / \mathrm{M}^{-1-}\right)$ mice found that the effects of BuTAC were near completely lost in $\mathrm{M} 2 / \mathrm{M4}^{-1-}$ double-knockout mice and potency of BuTAC was right-shifted in $\mathrm{M4}^{-1-}$ as compared with wild-type and $\mathrm{M} 2^{-1-}$ mice. The $\mathrm{M} 2 / \mathrm{M4}^{-1-}$ mice showed no altered sensitivity to the antipsychotic effects of either haloperidol or clozapine, suggesting that these compounds mediate their actions in CAR via a non-mAChR-mediated mechanism. These data support a role for the M4AChR subtype in mediating the antipsychotic-like activity of BuTAC and implicate M4AChR agonism as a potential novel therapeutic mechanism for ameliorating symptoms associated with schizophrenia.
\end{abstract}

Neuropsychopharmacology (2013) 38, 27I7-2726; do:I0.1038/npp.2013.186; published online 4 September 2013

Keywords: BuTAC; muscarinic receptors; acetylcholine; haloperidol; clozapine; conditioned avoidance response paradigm

\section{INTRODUCTION}

All currently available antipsychotic medications share dopamine D2 receptor antagonism as a common mechanism of action (Wadenberg et al, 2001). Despite being effective treatments, D2 antagonists have notable side effects as well as significant gaps in treatment response. Thus, there remains significant unmet clinical need for effective medications with novel mechanisms of action with improved efficacy and reduced side-effect profiles.

The muscarinic cholinergic system has potential as a novel therapeutic for schizophrenia: muscarinic antagonists are used to counter extrapyramidal side effects associated with potent dopamine D2 antagonists and muscarinic agonists have been hypothesized to be efficacious in treating positive and negative symptoms and cognitive deficits in schizo-

\footnotetext{
*Correspondence: Dr CC Felder, Neuroscience, Lilly Research Laboratories, Eli Lilly, Drop 0510 , Lilly Corporate Center, Indianapolis, IN, 46285, USA, Tel: + I 317276 5384, Fax: + I 3172767600 ,

E-mail: felder@lilly.com

Received I 8 January 20 13; revised 18 July 20 I3; accepted 22 July 20 I3; accepted article preview online 2 August 2013
}

phrenic patients (Bymaster et al, 2002). Most recently, a small placebo-controlled, double-blind clinical study with the muscarinic agonist xanomeline improved positive and negative symptoms, and cognitive deficits in treatmentresistant schizophrenics (Shekhar et al, 2008). Although xanomeline was relatively well tolerated in patients of this study, nonselective muscarinic agonists produce parasympathetic side effects that have limited their clinical utility.

There are currently five known muscarinic acetylcholine receptor (mAChR) subtypes (M1-M5AChR), all of which belong to the class A superfamily of G-protein-coupled receptors (Feldman et al, 1997; Kristiansen, 2004). High densities of the predominantly postsynaptically localized M1AChR subtype and presynaptically localized M2- and M4AChR subtypes have been found in limbic and forebrain areas implicated in the pathophysiology of schizophrenia, such as the cerebral cortex, hippocampus, and striatum, suggesting they may be promising targets for the development of novel antipsychotic medications (Bernard et al, 1992; Bymaster et al, 2003a; Felder et al, 2000; Hersch et al, 1994; Woolf, 1991).

BuTAC is a mAChR ligand that has previously been observed to exhibit efficacy in animal models 
predictive of antipsychotic activity in schizophrenia (Bymaster et al, 1998; Jones et al, 2005; Rasmussen et al, 2001). However, the precise $\mathrm{mAChR}$ subtype(s) responsible for the antipsychotic-like effects remain unresolved. Gene targeting technology has produced knockout mice with deletions of specific mAChRs that have assisted in the delineation of the roles that the different $\mathrm{mAChR}$ subtypes play in both physiological and pharmacological processes (Bymaster et al, 2003b). Such genetically modified animals were used here to determine the role of presynaptic $\mathrm{mAChR}$ subtypes (M2- and M4AChR) in mediating the antipsychotic effects of BuTAC.

Historically, BuTAC and the structurally similar PTAC have been described as M2-/M4AChR-preferring partial agonists with M1-/M3-/M5AChR antagonist activity, and both compounds exhibit efficacy in animal models predictive of antipsychotic activity in schizophrenia (Bymaster et al, 1998; Jones et al, 2005; Rasmussen et al, 2001). Our in vitro functional assay results outlined here slightly revise this historical selectivity profile for BuTAC. Assaying for mAChR functional activity with the antibody capture method for G-protein activation, we show that BuTAC exhibits full agonist activity at the M2AChR and equipotent partial agonist activity at the M1- and M4AChRs. In addition, BuTAC displays full antagonist activity at the M3- and M5AChRs. Using mice lacking individually the M2AChR, M4AChR, or both the M2- and M4AChRs, we demonstrate that BuTAC is effective in the conditioned avoidance response paradigm, a model predictive of antipsychotic-like efficacy, and that the M4AChR is an important subtype mediating effects in this assay.

\section{MATERIALS AND METHODS}

\section{Drugs}

BuTAC ([5R-(exo)]-6-[4-butylthio-1,2,5-thiadiazol-3-yl]-1azabicyclo-[3.2.1]-octane) was synthesized at Lilly Research Laboratories. Haloperidol and clozapine were purchased from Sigma Aldrich (St Louis, MO). BuTAC was mixed in $15 \mu \mathrm{l} 85 \%$ lactic acid and diluted with $0.9 \%$ saline. Haloperidol and clozapine were solubilized in sterile water with the addition of $10 \mu \mathrm{l} 85 \%$ lactic acid. All drugs were injected s.c. in a volume of $10 \mathrm{ml} / \mathrm{kg}$.

\section{In Vitro Muscarinic Selectivity Profile}

GTP- $\gamma$-[35S] binding was determined using the antibody capture scintillation proximity technique previously described by DeLapp et al (1999) in a 96-well plate format. Briefly, $100 \mu \mathrm{l}(20-40 \mathrm{fmol} /$ well $)$ of membrane preparation from CHO cells that stably express human M1-M5AChRs (PerkinElmer Life and Analytical Sciences, Boston, MA) were incubated for $30 \mathrm{~min}$ with $50 \mu \mathrm{l}$ of test compound. GDP ( $1 \mu \mathrm{M}$ final concentration) was added to M2 and M4 receptor membranes before incubation. Antagonist curves were generated in the presence of an $\mathrm{EC}_{80}$ concentration of oxotremorine-M. Following the incubation period, $50 \mu \mathrm{l}$ diluted GTP- $\gamma$-[35S] (500 pM final concentration; PerkinElmer Life and Analytical Sciences) was added to each well and incubated for $30 \mathrm{~min}$. The labeled membranes were then solubilized with $0.27 \%$ Nonidet P40 for $30 \mathrm{~min}$ followed by $60 \mathrm{~min}$ of incubation with $20 \mu \mathrm{l}$ (final dilution of $1: 400)$ of the appropriate rabbit polyclonal $\mathrm{G} \alpha$ antibody (Covance, Princeton, NJ). For the M1-, M3-, and M5AChR membranes, anti-G $\alpha_{\mathrm{q} / 11}$ antibody was used, whereas anti-G $\alpha_{i-3}$ antibody was used for the M2- and M4AChR membranes (Eli Lilly and Company, Indianapolis, IN). Following $60 \mathrm{~min}$ of incubation, $50 \mu \mathrm{l}(1.25 \mathrm{mg} /$ well $)$ antirabbit scintillation proximity assay (SPA) beads (GE Healthcare, Piscataway, NJ) were added per well and the plates incubated for an additional $3 \mathrm{~h}$. The plates were centrifuged for $10 \mathrm{~min}$ at $700 \times g$ and counted for $1 \mathrm{~min}$ per well using a Wallac MicroBeta TriLux scintillation counter (PerkinElmer). All incubations took place at room temperature in GTP-binding assay buffer $(20 \mathrm{mM}$ Hepes, $100 \mathrm{~mm} \mathrm{NaCl}, 5 \mathrm{mM} \mathrm{MgC1}$, $\mathrm{pH}$ 7.4). Data were analyzed using nonlinear regression for a sigmoidal concentration response curve (GraphPad Prism v. 4.0). Data were normalized to a full agonist response $(100 \mu \mathrm{M}$ oxotremorine-M) and percent efficacy $\left(\% E_{\max }\right)$ was expressed as a percentage of maximum signal observed in the presence of $100 \mu \mathrm{M}$ oxotremorine-M. Antagonist percent inhibition data were normalized to results generated with an $\mathrm{EC}_{80}$ concentration of oxotremorine-M (clozapine and haloperidol) or an $\mathrm{EC}_{90}$ concentration of acetylcholine (BuTAC). Mean relative $\mathrm{EC}_{50}, \mathrm{IC}_{50}$, and $\% E_{\max }$ values were calculated as a mean of at least three independent experiments \pm SEM. To allow for relevant comparisons between subtypes, the experimental system is routinely calibrated with reference compounds (oxotremorine-M, pilocarpine, $\mathrm{MCN}-\mathrm{A} 343$ ) to gauge full and partial agonism and ensure that the system is not under- or over-reporting functional efficacies. Radioligand binding assays were performed as described previously (Sauerberg et al, 1998).

\section{Subjects}

The generation and initial characterization of the M2AChR $\left(\mathrm{M} 2^{-I-}\right)$ and M4AChR (M4 ${ }^{-I-}$ ) knockout mice, as well as the M2/M4AChR double-knockout mice (M2/M4 ${ }^{-1-}$ ), has been described previously (Gomeza et al, 1999a; Gomeza et al, 2001). The $\mathrm{M} 2 / \mathrm{M}^{-1}{ }^{-}$double mice were expressed upon a mixed genetic background (129/Jae1 $(25 \%) \times 129 \mathrm{SvEv}(25 \%) \times$ CF-1 $(50 \%))$. Two lines of single $\mathrm{M} 2^{-1-}$ and $4^{-1-}$ knockout mice were tested in the present studies: (1) a mixed genetic background (M2 upon a 129Jae1/CF-1 background and M4 upon a 129SvEv/CF-1 background); and (2) a C57BL/6 genetic background, backcrossed for at least 10 breeding generations. Agematched littermate wild-type (WT; $+I+$ ) mice of the same genetic background were used as control animals for each knockout strain, with the exception of the single-point BuTAC replication in $\mathrm{M} 4^{-1-}$ mice on the $\mathrm{C} 57 \mathrm{BL} / 6$ background, where wild types were age-matched standard C57BL/6 mice, rather than littermates. Adult male mice were obtained from private colonies at Taconic Farms (Germantown, NY) and maintained in a light- and humidity-controlled room on a 12-h light/dark cycle (lights on at $0600 \mathrm{~h}$ ). Water and standard laboratory chow were available ad libitum. All procedures were conducted in strict adherence to the National Institutes of Health Guide for the Care and Use of Laboratory Animals. 
Table I Radioligand Binding and Functional Effects of BuTAC, Clozapine, and Haloperidol at the Five Muscarinic Acetylcholine Receptor Subtypes

\begin{tabular}{|c|c|c|c|c|c|}
\hline & MIAChR & M2AChR & M3AChR & M4AChR & M5AChR \\
\hline \multicolumn{6}{|l|}{ BUTAC } \\
\hline Rel pEC 50 & $9.22 \pm 9.80$ & $9.56 \pm 10.26$ & - \pm- & $|0.27 \pm| 0.3 \mid$ & $7.63 \pm 7.41$ \\
\hline$\% E_{\max }$ & $33.56 \pm 6.29$ & $136.53 \pm 17.20$ & - \pm- & $35.53 \pm|1.5|$ & $10.77 \pm 10.87$ \\
\hline Rel plC 50 & $9.03 \pm 10.01$ & - \pm- & $8.55 \pm 8.59$ & $9.19 \pm 9.13$ & $8.29 \pm 8.16$ \\
\hline$\%$ Inhibition & $57.27 \pm 2.35$ & - \pm- & $100.00 \pm 0.00$ & $57.55 \pm 3.22$ & $96.31 \pm 3.87$ \\
\hline \multicolumn{6}{|l|}{ Clozapine } \\
\hline Rel pEC 50 & - \pm- & $6.63 \pm 6.95$ & - \pm- & - \pm- & - \pm- \\
\hline$\% E_{\max }$ & - \pm- & $25.78 \pm 3.78$ & - \pm- & - \pm- & - \pm- \\
\hline Rel plC $C_{50}$ & $7.35 \pm 8.67$ & $5.96 \pm 6.75$ & $6.23 \pm 7.19$ & $6.52 \pm 6.96$ & $6.39 \pm 6.74$ \\
\hline \multicolumn{6}{|l|}{ Haloperidol } \\
\hline$\% E_{\max }$ & - \pm- & - \pm- & - \pm- & - \pm- & - \pm- \\
\hline Rel plC 50 & $4.65 \pm 5.08$ & $4.45 \pm 4.92$ & - \pm- & $4.59 \pm 5.04$ & - \pm- \\
\hline$\%$ Inhibition & $69.97 \pm 4.11$ & $79.11 \pm 4.14$ & - \pm- & $90.12 \pm 17.12$ & - \pm- \\
\hline
\end{tabular}

Plasma membranes were purified from cell lines stably expressing the five human muscarinic receptor subtypes and subjected to GTP $[$ [35S] binding as described in the Materials and Methods. For all compounds, $\mathrm{pEC}_{50}$ values and \% $\mathrm{E}_{\max }$ were measured over a full concentration response curve for each ligand and are expressed as the percent maximum signal observed at each receptor subtype in the presence of oxo-M (I00 $\mu \mathrm{M})$. For clozapine and haloperidol, plC $\mathrm{C}_{50}$ values and percent inhibition were measured in the presence of an experimentally determined $\mathrm{EC}_{80}$ concentration of oxo-M. For BuTAC, pIC $\mathrm{C}_{50}$ values and percent inhibition were measured in the presence of an experimentally determined $\mathrm{EC}_{90}$ concentration of $\mathrm{ACh}$ (determined for each individual subtype). For BuTAC, $K_{i}$ values were determined by displacement of the radiolabeled antagonist $\left[{ }^{3} \mathrm{H}\right]$-N-methylscopolamine. Data represent the mean $\pm \mathrm{SEM}$ from at least three independent experiments (each performed in duplicate) and concentrations are expressed as the negative log-transformed values (M).

\section{Apparatus}

Mice were trained and tested in standard mouse operant shuttle-avoidance chambers (Coulbourn Instruments, Allentown, PA) placed within sound-attenuating chambers. The apparatus consisted of two adjacent stainless steel compartments $(17 \mathrm{~W} \times 18 \mathrm{D} \times 29 \mathrm{H} \mathrm{cm})$ with clear Plexiglas front and back walls. A stainless steel wall containing a guillotine-style shuttle door $(7 \times 8 \mathrm{~cm})$ separated the compartments. The floor grid comprised $0.25 \mathrm{~cm}$ diameter stainless steel rods, placed $1 \mathrm{~cm}$ apart (center-to-center). A house light (1.12 watts) located $\sim 27 \mathrm{~cm}$ above the floor grid on each side of the chamber served as the conditioned stimulus (CS).

\section{Behavioral Testing Procedures}

Mice received five training sessions per week. Each session consisted of 50 trials, with an intertrial interval of $30 \mathrm{~s}$. The illumination of a house light and the opening of the shuttle door signaled trial onset. For each trial, mice received $10 \mathrm{~s}$ to perform a shuttle response upon trial onset (termed the avoidance period). If a shuttle response was not made after $10 \mathrm{~s}$, a mild footshock $(0.75 \mathrm{~mA})$ was initiated for $10 \mathrm{~s}$ (shock period). Shuttle responses performed during the 10-s avoidance period were recorded as avoidance responses and no shocks were received. Shuttle responses made during the 10 -s shock period were recorded as escape responses. If no shuttle response was made during the shock period, an escape failure was recorded, the shuttle door was closed, and the shock was terminated. Movements of the animals from one side to the other were measured by photocells and recorded for offline analysis. For all mice, the session was terminated after 50 trials (avoidance + escape), or if 20 escape failures occurred.

Mice were trained for $\sim 3$ weeks until performance was consistently above $90 \%$ avoidance responding (45 out of 50 trials). Drug treatments began once the mice performed $>90 \%$ avoidance responses on three consecutive days. A within-subject experimental design was used for drug testing, and the day before testing of a drug dose, mice received vehicle injections. If mice achieved criterion on the vehicle day ( $>90 \%$ avoidance), drug treatments were administered on the following day. For each test compound, doses were administered in ascending order, two doses per week, with at least 3 days of washout between doses.

\section{Statistics}

Separate 2-factor (1-within: dose; 1-between: genotype) mixed-design ANOVAs were used for each cohort to evaluate the effects of each drug on the percentage conditioned avoidance responses and the percentage escape failures (JMP statistics, SAS, Cary, NC). To control for inflated type I error because of lack of sphericity, degrees of freedom were adjusted using the Greenhouse-Geisser correction. Statistically significant effects (main effects and/or the interaction) were followed-up with post hoc 

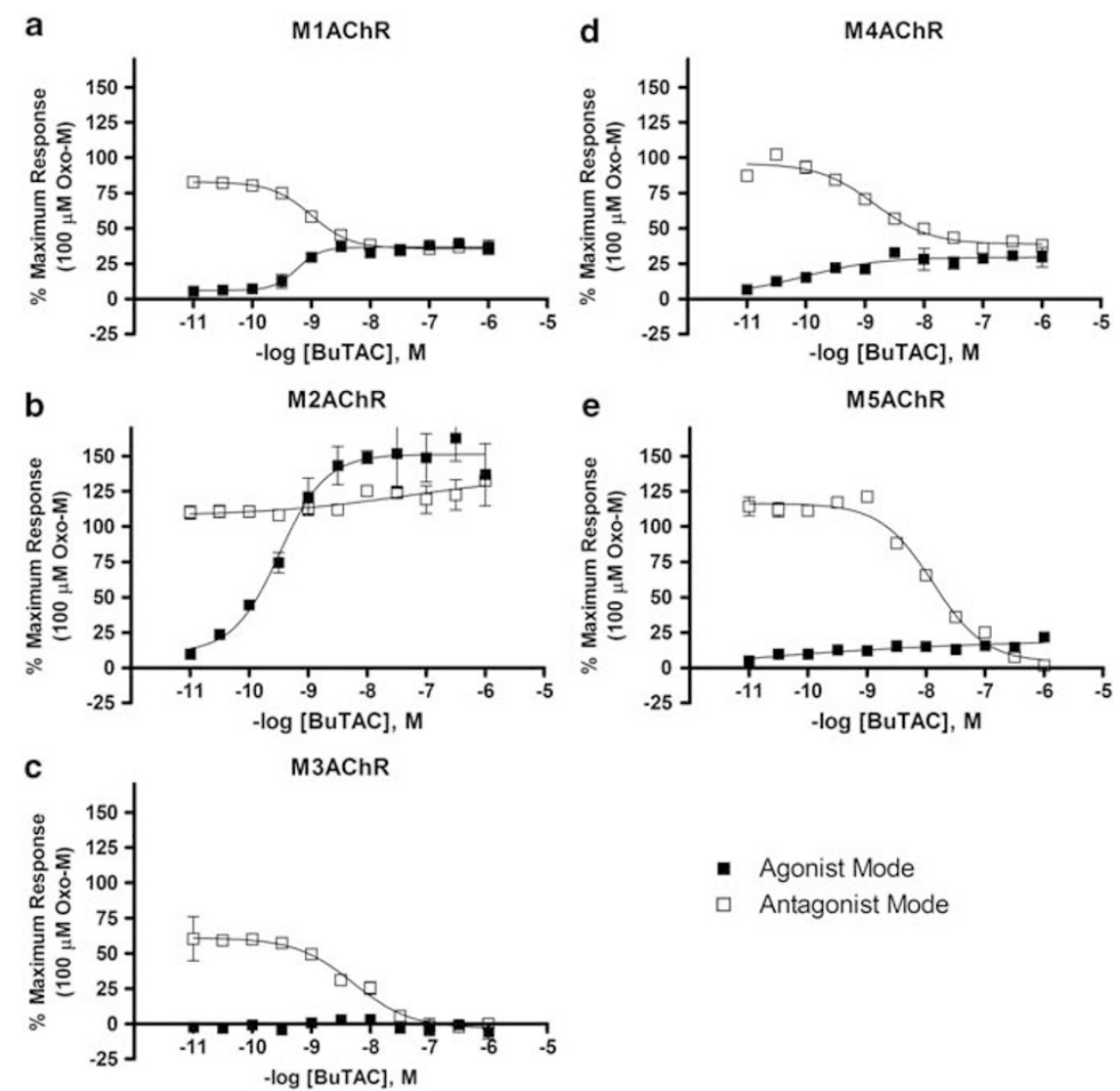

- Agonist Mode

․ Antagonist Mode

Figure I Effect of BuTAC on GTP- $\gamma$-[35S] binding in membranes prepared from CHO cells heterologously expressing hMI-hM5AChRs (panels a-e, respectively). Agonist $\% E_{\max }$ data are expressed as the percentage of maximal signal observed in the presence of the nonselective orthosteric $m A C h R$ agonist oxotremorine-M (I00 $\mu \mathrm{M})$ and \% inhibition data represent the relative antagonism of the agonist response observed using an experimentally determined $\mathrm{EC}_{90}$ concentration of $\mathrm{ACh}$; potency data are expressed as the mean $\pm \mathrm{SD}$ of at least three separate experiments, each performed in duplicate. Acetycholine was used in antagonist assays instead of oxotremorine-M to more accurately represent potential inhibition of endogenous signaling.

comparisons using Tukey's HSD test $(\alpha=0.05)$ for all comparisons, where the family of comparisons of primary interest were: (1) within each dose, the knockout line(s) against the wild-type; and (2) within each genotype, the drug dose(s) against the respective vehicle dose.

\section{RESULTS}

\section{Functional Effects of BuTAC at mAChR Subtypes}

The functional selectivity of BuTAC, as determined by GTP$\gamma$-[35S] binding, was compared with clozapine and haloperidol across the five human muscarinic receptor subtypes (Table 1). BuTAC displayed full agonist activity at the $\operatorname{M} 2 \mathrm{AChR}\left(\mathrm{pEC}_{50}=9.56 \pm 10.26 \mathrm{M} ; \% E_{\max }=136.53 \pm 17.20 \%\right)$ and partial agonist activity at the M1- and M4AChR subtypes $\quad\left(\mathrm{pEC}_{50}=9.22 \pm 9.80\right.$ and $10.27 \pm 10.31 \mathrm{M}$, respectively; $\% E_{\max }=33.56 \pm 6.29$ and $35.53 \pm 11.51 \%$, respectively; Figure 1a, b, and d). BuTAC demonstrated concomitant partial antagonism at the M1 and M4 subtypes $\left(\mathrm{pIC}_{50}=9.03 \pm 10.01\right.$ and $9.19 \pm 9.13$, respectively; \% inhibition $=57.27 \pm 2.35$ and $57.55 \pm 3.22 \%$, respectively; Figure 1a and d) as well as full antagonist activity at the M3 and M5 AChRs $\left(\mathrm{pIC}_{50}=8.55 \pm 8.59\right.$ and $8.29 \pm 8.16 \mathrm{M}$, respectively; $\%$ inhibition $=100 \pm 0$ and $96.31 \pm 3.87 \%$, respectively). In contrast to the activity profile of BuTAC, the typical antipsychotic haloperidol showed no agonist activity at any of the five mAChR subtypes and displayed weak partial antagonist activity at the M1-, M2-, and M4AChRs $\quad\left(\mathrm{pIC}_{50}=4.65 \pm 5.08,4.45 \pm 4.92\right.$, and $4.59 \pm$ $5.04 \mathrm{M}$, respectively; \% inhibition $=69.97 \pm 4.11,79.11 \pm$ 4.14 , and $90.12 \pm 17.12 \%)$. The atypical antipsychotic clozapine displayed weak partial agonism at the M2AChR $\left(\mathrm{pEC}_{50}=6.63 \pm 6.95 \mathrm{M} ; \% E_{\max }=25.78 \pm 3.78 \%\right)$ and exhibited near-full antagonism at all other $\mathrm{mAChR}$ subtypes (M1, M3-, M4- and M5AChR; \% inhibition $=89.92 \pm 6.85$, $95.06 \pm 2.80,97.94 \pm 1.15$, and $93.88 \pm 6.35 \%$, respectively).

\section{Conditioned Avoidance Responding in Double M2/M4 ${ }^{-1-}$ Mice (Mixed Background)}

Strikingly, the antipsychotic-like effects of BuTAC were nearly absent in the mice lacking both the M2- and M4AChRs (mixed genetic background), showing a $>100$ fold decrease in sensitivity to the avoidance-suppressing effects of BuTAC (Figure 2a). The main effects of genotype and dose were observed on the percent avoidance responses $\left(\mathrm{F}_{1,22}=425.57, P<0.0001 ; \mathrm{F}_{3,63}=125.17, P<0.0001\right)$, as well as significant dose $\times$ genotype interaction $\left(\mathrm{F}_{3,63}=\right.$ 77.23, $P<0.0001)$. The post hoc analyses revealed that although BuTAC suppressed avoidance responding in WT mice at doses of $0.03,0.1,0.3,1$, and $3 \mathrm{mg} / \mathrm{kg} v s$ their vehicle 

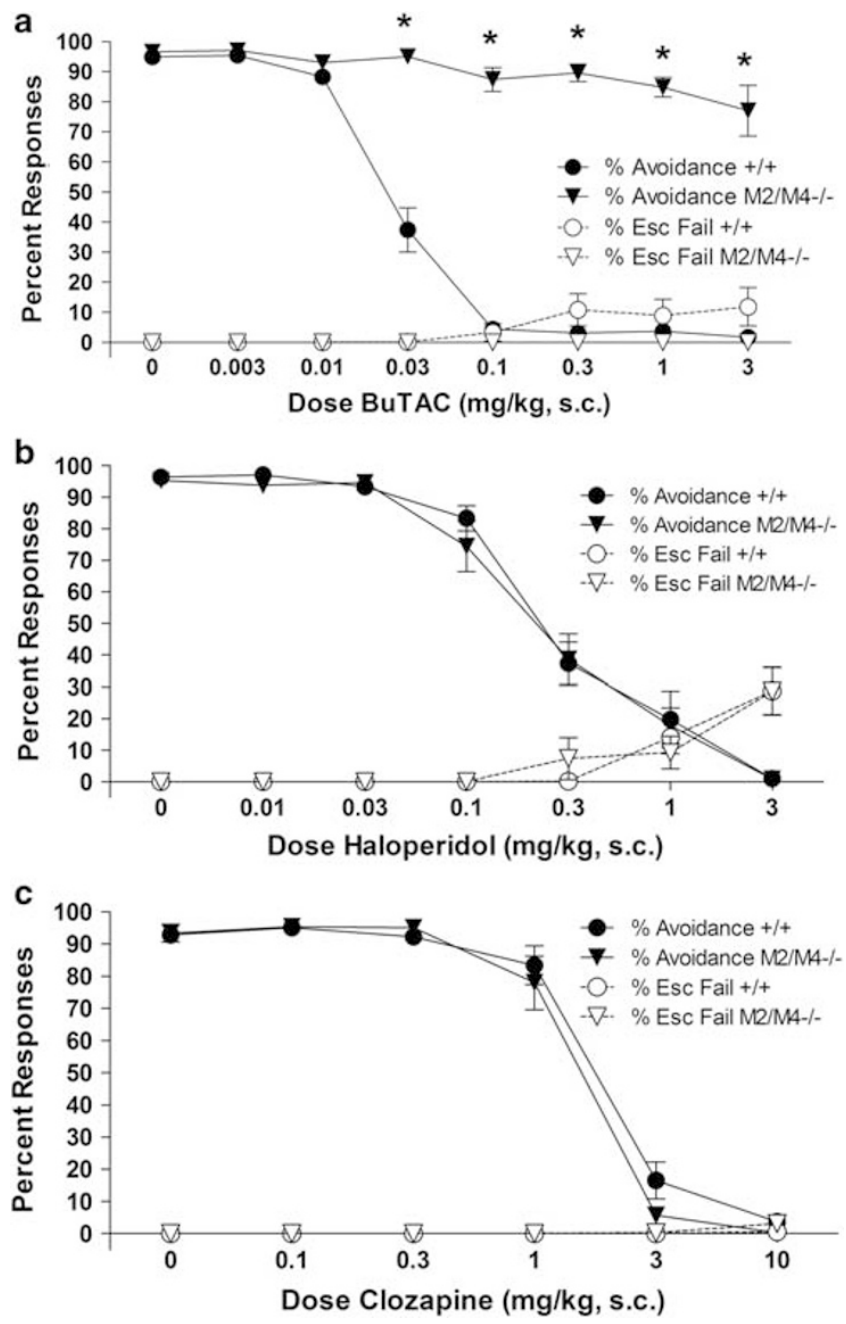

Figure 2 Effects of BuTAC, haloperidol, and clozapine on the mean $( \pm$ SEM) percent conditioned avoidance responses and escape failures in M2/M4 double-knockout (M2/M4-1- ) and WT mice. (a) BuTAC produced antipsychotic-like effects in wild-type (WT) mice, as demonstrated by the dose-dependent suppression of avoidance responding. In contrast, $\mathrm{M} 2 /$ $\mathrm{M}^{-1}{ }^{-}$mice showed a $>100$-fold decrease in sensitivity to the

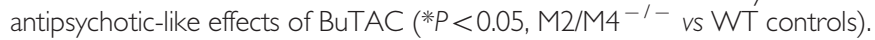
Detailed dose and genotype comparisons are reported in Results. No significant differences were observed in percent escape failures between $\mathrm{M} 2 /$ $\mathrm{M4}^{-1-}$ and WT mice, indicating reduced propensity to produce extrapyramidal side effects (Ps>0.05). (b) Antipsychotic-like effects of haloperidol were not altered in $\mathrm{M} 2 / \mathrm{M}^{-1}{ }^{-}$mice, as indicated by the lack of genotype or interaction effects on avoidance responding between $\mathrm{M} 2 /$ $\mathrm{M4}^{-1-}$ and WT mice. Haloperidol dose-dependently increased escape failures in both $\mathrm{M} 2 / \mathrm{M4}^{-1-}$ and $\mathrm{WT}$ mice, consistent with its propensity to produce extrapyramidal side effects in humans. Detailed dose and genotype comparisons are reported in Results. (c) Antipsychotic-like effects of clozapine were not altered in $\mathrm{M} 2 / \mathrm{M}^{-1-}$ mice, as indicated by the lack of genotype or interaction effects on avoidance responding between $\mathrm{M} 2 / \mathrm{M}^{-1-}$ and $\mathrm{WT}$ mice. Clozapine did not significantly increase escape failures in either $\mathrm{M} 2 / \mathrm{M}^{-1-}$ or WT mice. Detailed dose and genotype comparisons are reported in Results.

control dose, avoidance responding in $\mathrm{M} 2 / \mathrm{M} 4^{-1-}$ mice was suppressed only at the $3 \mathrm{mg} / \mathrm{kg}$ dose relative to their vehicle control, and BuTAC suppressed avoidance responding to a greater extent in WT mice relative to $\mathrm{M} 2 / \mathrm{M}^{-1-}$ mice at doses of $0.03 \mathrm{mg} / \mathrm{kg}$ and greater. No significant main effects or interaction were observed on the percent escape failures in M2/M4 ${ }^{-1-}$ and WT mice (all $P s>0.05$ ).

$\mathrm{M} 2 / \mathrm{M}^{-1-}$ and WT mice showed similar sensitivity to the antipsychotic-like effects of both haloperidol and clozapine (Figure $2 \mathrm{~b}$ and $\mathrm{c}$, respectively). A main effect of dose was revealed on the percent avoidance responses in mice receiving haloperidol $\left(\mathrm{F}_{3,44}=189.79, \quad P<0.0001\right)$, indicating a dose-dependent suppression in the absence of a genotype main effect or interaction (all $P s>0.05$ ). The post-hoc analyses revealed that haloperidol suppressed avoidance responding in WT mice at doses of $0.3,1$, and $3 \mathrm{mg} / \mathrm{kg}$ and in M2/M4 ${ }^{-1-}$ mice at doses of $0.1,0.3,1$, and $3 \mathrm{mg} / \mathrm{kg}$, as compared with their respective vehicle doses. A main effect of dose was also revealed on the percent escape failures $\left(\mathrm{F}_{2,31}=12.89, P<0.0001\right)$ in the absence of a genotype main effect or interaction (all $P s>0.05$ ), where post hoc analyses indicated that haloperidol dose-dependently produced escape failures in both $\mathrm{M} 2 / \mathrm{M}^{-1-}$ and WT mice at the highest concentration $(3 \mathrm{mg} / \mathrm{kg})$.

A main effect of dose was observed on the percent avoidance responses in mice receiving clozapine, indicating a dose-dependent disruption of avoidance responding $\left(\mathrm{F}_{2,23}=349.75, P<0.0001\right.$; Figure $\left.2 \mathrm{c}\right)$, in the absence of a genotype main effect or interaction (all $P s>0.05$ ). The post hoc analyses revealed that clozapine suppressed avoidance responding in both WT and M2/M4 ${ }^{-1-}$ mice at doses of 3 and $10 \mathrm{mg} / \mathrm{kg}$ as compared with their respective vehicle doses. In contrast to haloperidol, clozapine did not significantly increase escape failures (main effects and interaction: all $P S>0.05$ ).

\section{Conditioned Avoidance Responding in $\mathrm{M}^{-1-}$ and M4 ${ }^{-l-}$ Mice (Mixed CF-1 $\times 129$ Substrain Background)}

Recall that $\mathrm{M} 2^{-1-}$ mice were bred upon a mixed 129JAE1 $\times$ CF-1 genetic background, whereas $\mathrm{M} 4^{-1-}$ mice were maintained on a $129 \mathrm{SvEv} \times \mathrm{CF}-1$ background. Of an initial cohort of $14 \mathrm{M} 2 \mathrm{WT}$ mice, 10 failed to achieve avoidance response criterion, leaving few to progress to drug testing $(N=4)$. Thus, statistical analyses were only conducted on $\mathrm{M}^{-1-}$ and WT mice. As seen in Figure 3, BuTAC significantly disrupted avoidance responding similarly in both $\mathrm{M}^{-l-}$ and WT mice, as indicated by a main effect of dose $\left(\mathrm{F}_{2,26}=99.45, P<0.0001\right)$ and a lack of a main effect of genotype or genotype $\times$ dose interaction $(P s<0.05)$. The post hoc analyses revealed that BuTAC significantly reduced avoidance responding in WT and $\mathrm{M} 4^{-1-}$ mice at doses of $0.03,0.1,0.3,1$, and $3 \mathrm{mg} / \mathrm{kg}$ as compared with their respective vehicle doses.

BuTAC dose-dependently increased escape failures, as indicated by a main effect of dose $\left(\mathrm{F}_{2,19}=7.88, P=0.005\right.$; Figure 3). A significant main effect of genotype was observed on the percent escape failures $\left(\mathrm{F}_{1,12}=7.05, P<0.03\right)$, as well as a dose $\times$ genotype interaction $\left(\mathrm{F}_{2,19}=5.84, P<0.02\right)$. The post hoc analyses revealed that BuTAC significantly increased escape failures only in WT mice at doses of $0.3,1$, and $3 \mathrm{mg} / \mathrm{kg} v \mathrm{~s}$ their respective vehicle dose, and WT mice demonstrated significantly more escape failures than $\mathrm{M} 4^{-1-}$ mice at the 1 and $3 \mathrm{mg} / \mathrm{kg}$ doses.

Although not statistically analyzed because of low $N, \mathrm{M} 2^{-I-}$ and WT mice exhibited comparable effects of BuTAC: for instance, doses of 0.03 and $0.1 \mathrm{mg} / \mathrm{kg}$ produced $34.7 \%$ vs $28.5 \%$ and $21.3 \%$ vs $8.0 \%$ avoidances in $\mathrm{M}^{-1-}$ 


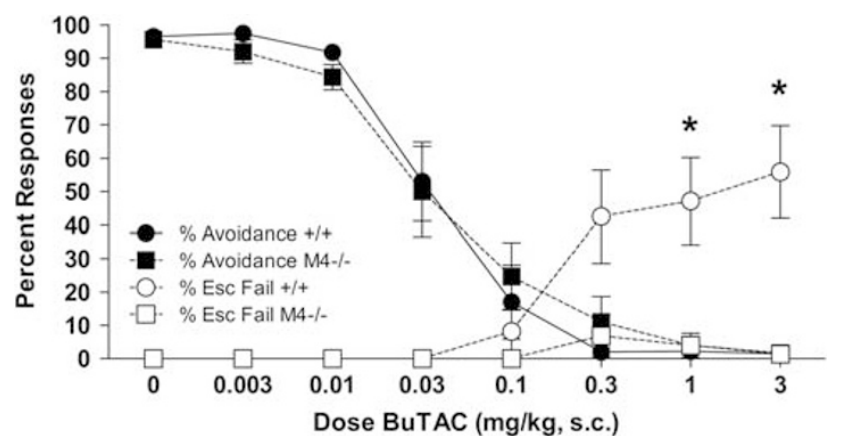

Figure 3 Effects of BUTAC on the mean ( \pm SEM) percent conditioned avoidance responses and escape failures in $\mathrm{M}^{-1-}$ and wild-type (WT) mice on a mixed genetic background. BuTAC produced antipsychotic-like effects in all mice tested, as demonstrated by the dose-dependent suppression of avoidance responding. No significant differences between genotypes were observed in the percent avoidance responses (Ps $>0.05)$. However, BuTAC significantly increased escape failures in WT, but not $\mathrm{M}^{-1-}$, mice on the mixed genetic background $\left(* \mathrm{P}<0.05, \mathrm{M} 2 / \mathrm{M}^{-1-}\right.$ vs WT controls). Detailed genotype and dose comparisons are reported in Results.

and WT mice, respectively. Moreover, a $3 \mathrm{mg} / \mathrm{kg}$ dose of BuTAC produced $0.67 \%$ escape failures in $\mathrm{M} 2^{-1-}$ mice and $0.0 \%$ escape failures in WT mice.

\section{Conditioned Avoidance Responding in $\mathrm{M}^{-1-}$ and M4 ${ }^{-1-}$ Mice (C57BL/6 Background)}

Figure $4 \mathrm{a}$ shows the effects of BuTAC on the mean $( \pm$ SEM) percent conditioned avoidance responses and escape failures in $\mathrm{M} 2^{-1-}, \mathrm{M}^{-1-}$, and $\mathrm{WT}$ mice $(\mathrm{C} 57 \mathrm{BL} / 6$ genetic background). BuTAC dose-dependently disrupted conditioned avoidance responding, which was also dependent on genotype, as indicated by significant main effects of dose $\left(\mathrm{F}_{3,96}=114.91, \quad P<0.0001\right), \quad$ genotype $\quad\left(\mathrm{F}_{2,35}=21.52\right.$, $P<0.0001)$, and a dose $\times$ genotype interaction $\left(\mathrm{F}_{6,96}=5.92\right.$, $P<0.0001)$. The post hoc analyses determined that $\mathrm{M}^{-1-}$ mice were significantly less affected by each dose of BuTAC than were WT controls. In contrast, however, $\mathrm{M} 2^{-1-}$ and WT mice did not differ in their responsiveness to each dose of BuTAC. Both $\mathrm{M} 2^{-1-}$ and WT mice demonstrated reduced avoidance responding at all doses $(0.01-0.3 \mathrm{mg} / \mathrm{kg})$ as compared with their respective vehicle doses, whereas $\mathrm{M} 4^{-I-}$ mice demonstrated reduced avoidance responding only at $0.03,0.1$, and $0.3 \mathrm{mg} / \mathrm{kg}$ as compared with their respective vehicle dose. A main effect of dose was also revealed on the percent escape failures $\left(\mathrm{F}_{2,38}=4.13, P<0.05\right)$ in the absence of a genotype main effect or interaction (all $P s>0.05)$; however, post hoc analyses indicated there were no significant differences in individual comparisons.

The effects of haloperidol on the mean $( \pm$ SEM) percent conditioned avoidance responses and escape failures in $\mathrm{M} 2^{-l-}, \mathrm{M} 4^{-1-}$, and WT mice are depicted in Figure $4 \mathrm{~b}$. Haloperidol dose-dependently disrupted avoidance responding (main effect of dose: $\mathrm{F}_{2,80}=105.61, P<0.0001$ ]. A main effect of genotype was observed on the percent avoidance responses $\left(\mathrm{F}_{2,34}=4.07, P<0.03\right)$, as well as a dose $\times$ genotype interaction $\left(\mathrm{F}_{5,80}=3.05, P<0.02\right)$. The post hoc tests indicated that both $\mathrm{M}^{-1-}$ and WT mice demonstrated reduced avoidance responding at $0.3-10 \mathrm{mg} /$ a
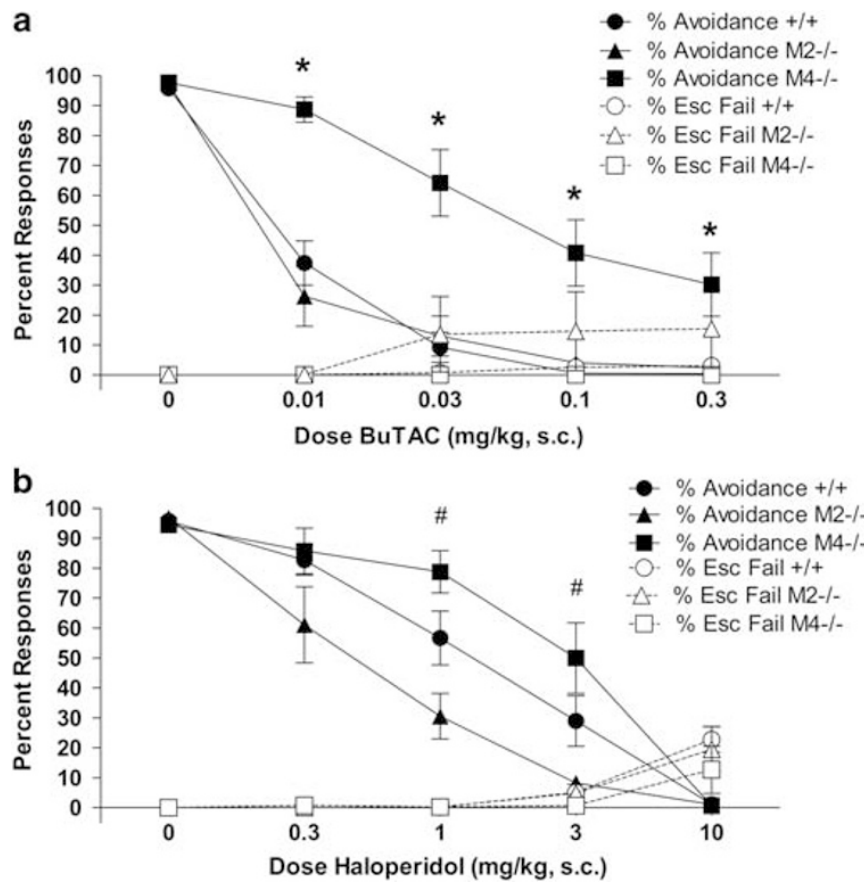

Figure 4 Effects of BuTAC and haloperidol on the mean ( \pm SEM) percent conditioned avoidance responses and escape failures in $\mathrm{M}^{-1-}$ $\mathrm{M4}^{-1-}$ single-knockout, and wild-type (WT) mice on a B6 background. (a) BUTAC produced antipsychotic-like effects in all mice tested, as demonstrated by the dose-dependent suppression of avoidance responding. $\mathrm{M}^{-1-}$ mice demonstrated a 30 -fold less sensitivity to the antipsychotic effects of BuTAC compared with $\mathrm{M}^{-1-}$ and WT mice (*P $<0.05$ vs WT controls). Detailed dose and genotype comparisons are reported in Results. Importantly, BuTAC did not significantly increase escape failures in any of the mice, indicating reduced propensity to produce extrapyramidal side effects (all Ps > 0.05). (b) Haloperidol produced antipsychotic-like effects in all mice tested, as demonstrated by the dose-dependent suppression of avoidance responding. Although $\mathrm{M}^{-1-}$ mice showed less sensitivity to the antipsychotic-like effects of BuTAC than WT or $\mathrm{M}^{-1-}$ mice, relative to their respective vehicle controls, avoidance responses following haloperidol treatment were not significantly different in either $\mathrm{M}^{-1-}$ or $\mathrm{M}^{-1-}$ mice vs WT animals at any dose tested ( ${ }^{\#} P<0.05$ vs $\left.\mathrm{M}^{-1-}\right)$. Haloperidol dosedependently increased escape failures, consistent with its propensity to produce extrapyramidal side effects in humans. Detailed dose and genotype comparisons are reported in Results.

$\mathrm{kg}$ as compared with their respective vehicle doses, whereas $\mathrm{M}^{-1-}$ mice demonstrated reduced avoidance responding only at 3 and $10 \mathrm{mg} / \mathrm{kg}$ as compared with their respective vehicle dose. As neither $\mathrm{M}^{-1-}$ nor $\mathrm{M}^{-1-}$ mice differed significantly from WT mice at any dose tested, the dose $x$ genotype interaction appears to have been largely driven by a significant difference between $\mathrm{M} 4^{-1-}$ and $\mathrm{M} 2^{-1-}$ mice at the 1 and $3 \mathrm{mg} / \mathrm{kg}$ doses, where $\mathrm{M} 4^{-1-}$ mice performed significantly more avoidance responses than $\mathrm{M} 2^{-1-}$ mice. A main effect of dose was also revealed on the percent escape failures $\left(\mathrm{F}_{1,40}=17.47, P<0.0001\right)$ in the absence of a genotype main effect or interaction (all $P$ s $>0.05$ ); however, post hoc analyses indicated haloperidol significantly induced escape failures only in WT mice at the $10 \mathrm{mg} / \mathrm{kg}$ dose.

To confirm the antipsychotic-like efficacy and genotype effects of BuTAC, a single dose of $0.03 \mathrm{mg} / \mathrm{kg}$ was tested in a separate cohort of $\mathrm{M} 4^{-1-}$ and WT mice on the C57BL/6 background. As in the previous experiments, BuTAC significantly reduced avoidance responses, indicated by 
a significant main effect of dose on percent avoidance responses (Table 2; $F_{1,27}=171.79, P<0.0001$ ). A significant main effect of genotype was observed $\left(\mathrm{F}_{1,27}=11.94\right.$, $P<0.002)$, as was a significant dose $\times$ genotype interaction $\left(\mathrm{F}_{1,27}=16.03, P<0.001\right)$. The post hoc tests indicated that M4 ${ }^{-1-}$ mice receiving $0.03 \mathrm{mg} / \mathrm{kg}$ BuTAC produced significantly more avoidance responses than WT mice $(P<0.05)$, confirming the genotype-dependent effects of BuTAC. The $0.3 \mathrm{mg} / \mathrm{kg}$ dose of BuTAC did not significantly increase escape failures (main effects and interaction: all Ps $>0.05)$.

\section{DISCUSSION}

Previously, BuTAC had been suggested to act as a M2-/ M4AChR-preferring agonist with antagonist activity at the M1-, M3-, and M5AChRs (Shannon et al, 1999; Rasmussen et al, 2001). However, the results of the functional GTP- $\gamma$ $\left[{ }^{35} \mathrm{~S}\right]$ binding studies outlined here indicate that BuTAC acts as a relatively equipotent M1-/M2-/M4AChR-preferring agonist with relatively full efficacy at the M2AChR and partial agonist activity at both the M1- and M4AChRs (Table 1 and Figure 1a, b, and d). Our results also show that BuTAC demonstrates full antagonist activity at the M3- and M5AChRs, confirming previous findings (Figure 1c and e) (Shannon et al, 1999; Rasmussen et al, 2001). These data modify the former observations made by Shannon et al (1999) concerning the functional activity profile for BuTAC. Such differences between in vitro study outcomes likely reflect the technical advancements made in functional assay development since the initial characterization of this molecule. As has been demonstrated here, BuTAC displayed potent, but nonselective, displacement of the radiolabeled antagonist $\left[{ }^{3} \mathrm{H}\right]-\mathrm{NMS}$ (Table 1). Such results highlight the importance of in vitro functional studies, which were required here, in combination with genetic deletion models, to reveal the receptor subtype selectivity profile for BuTAC and the subsequent physiological relevance. BuTAC exhibits antipsychotic-like effects in animal models of psychosis, including apomorphine-induced climbing and apomorphine-induced disruption of prepulse inhibition (Jones et al, 2005; Rasmussen et al, 2001). The present study extended these previous findings by demonstrating antipsychotic-like activity in the mouse conditioned avoidance response (CAR) paradigm. Moreover, the contribution of presynaptic $\mathrm{mAChR}$ signaling (via the predominantly presynaptically localized M2- and M4AChRs) was evaluated in corresponding gene deletion mice. The role of the predominantly postsynaptically localized M1AChR in mediating the antipsychotic-like effects of BuTAC in vivo was not specifically evaluated during these studies, leaving open the possibility that M1AChR activity contributes to the preclinical pharmacology of BuTAC.

BuTAC exhibited an atypical antipsychotic-like profile in the CAR assay and, when compared with wild-type and $\mathrm{M} 2^{-1-}$ mice, $\mathrm{M} 4^{-1-}$ mice exhibited reduced sensitivity to the effects of BuTAC upon conditioned avoidance responding, indicating that BuTAC mediates antipsychotic-like activity in this assay predominantly via the $\mathrm{M} 4 \mathrm{AChR}$ subtype. Its efficacy was completely lost in double M2/ M4AChR knockout mice, suggesting that although likely predominantly mediated by $\mathrm{M} 4 \mathrm{AChR}$, the efficacy of
Table 2 Effect of BuTAC on Conditioned Avoidance Responding in $\mathrm{M4}^{-1-}$ and wild-type (WT) Mice

\begin{tabular}{|c|c|c|c|c|}
\hline & \multicolumn{2}{|c|}{$\begin{array}{c}\text { \% Avoidance responses } \\
( \pm \text { SEM })\end{array}$} & \multicolumn{2}{|c|}{$\begin{array}{l}\text { \% Escape failures } \\
\quad( \pm \text { SEM })\end{array}$} \\
\hline & WT & $M 4^{-1-}$ & WT & $M 4^{-1-}$ \\
\hline Vehicle control & $97.2( \pm 1.2)$ & $95.8( \pm 0.7)$ & 0 & 0 \\
\hline BuTAC $0.03 \mathrm{mg} / \mathrm{kg}$ & $11.2( \pm 4.1)^{\#}$ & $50.0( \pm 8.7)^{* \#}$ & $02( \pm 02)$ & 0 \\
\hline
\end{tabular}

The effect of a single active dose of BUTAC was tested in a separate cohort of $\mathrm{M}^{-1-}$ and WT mice. Results confirmed the antipsychotic-like effects of BUTAC without concomitant increases in escape failures. Results also confirmed decreased sensitivity to BuTAC in $M 4^{-1-}$ mice ${ }^{*} P<0.05$ vs WT controls, ${ }^{\#} P<0.05$ vs respective vehicle controls). Importantly, BuTAC did not increase escape failures in any mice tested. Detailed statistical analyses are reported in Results.

BuTAC may also be somewhat dependent upon the integrity of M2AChRs. The striking lack of BuTAC activity in the $\mathrm{M} 2 / \mathrm{M} 4^{-1-}$ mice was contrasted with normal (ie, comparable activity to WT mice) avoidance response effects to haloperidol and clozapine.

Evaluation of BuTAC in single $\mathrm{M} 2^{-1-}$ and $\mathrm{M}^{-1-}$ mice, against a mixed (CF- $1 \times 129$ substrain) genetic background, revealed that $\mathrm{M} 4^{-1-}$ mice were less sensitive to BuTAC only at higher doses that produced escape failures in the WT controls of this particular hybrid mouse strain. As shown by He and Shippenberg (2000), different strains of mice exhibit altered basal dopamine dynamics and respond differently to dopamine agonists such as cocaine. In our study, the mice on the hybrid background may have a higher M4 dependence in the nigrostriatal (A9) motor pathways relative to the mesolimbic (A10) pathway, hence offering a possible explanation on why genotypic differences of BuTAC emerged only at higher doses that produced escape failures in WT mice. Consistent with this hypothesis, the $\mathrm{C} 57 \mathrm{Bl} / 6$ strain is less sensitive to escape failures in the CAR assay. Although not analyzed because of low power, the $\mathrm{M} 2^{-1-}$ mice on the hybrid background were comparably affected by BuTAC relative to WT mice, suggesting that a target(s) other than M2- or M4AChRs mediated BuTAC activity at lower doses, but that the M4AChR mediated high-dose motor impairment effects.

Because of the difficulty in training $\mathrm{M}^{-1-}$ mice on a CF$1 \times 129$ Jae 1 background to a $90 \%$ avoidance criterion in the CAR assay and in interpreting the relative role of M2- vs M4AChRs in BuTAC CAR pharmacology in mice with differing genetic backgrounds, we also tested BuTAC in C57Bl/6-derived $\mathrm{M}^{-1-}$ and $\mathrm{M} 4^{-1-}$ mice. In these studies, it was apparent that the M2AChR served little role in the effect of BuTAC, whereas in M4 $4^{-1-}$ mice, sensitivity to BuTAC was a $\sim 30$-fold right-shifted. This finding of reduced BuTAC potency in $\mathrm{M} 4^{-1-}$ mice was replicated in a separate cohort. Although not tested in this study, previous reports have demonstrated that mice lacking M4AChRs exhibit enhanced sensitivity to dopaminergic agonists (Gomeza et al, 1999b), suggesting that the rightward shift in the CAR assay demonstrated here may be related to altered M4AChR modulation of dopamine tone. Although our data in $\mathrm{M} 2^{-1-}$ and $\mathrm{M} 4^{-1-}$ mice strongly implicate M2 and M4, it should be noted that both M1 and 
M5 receptors have also been postulated to regulate dopaminergic pathways. For example, $\mathrm{M}^{-1-}$ mice show a heightened locomotor response to d-amphetamine (Gerber et al, 2001), and M5 receptors are localized on dopamine cell bodies in the VTA, suggesting direct modulation (Schmidt et al, 2010; Steidl et al, 2011). Indeed, $\mathrm{M}^{-1-}$ mice have demonstrated behavioral, neurochemical, and electrophysiological responses consistent with modulation of dopaminergic neurotransmission (Forster et al, 2002; Schmidt et al, 2010). Nonetheless, the data presented here strongly implicate a role for M4 receptors in mediating the efficacy of BuTAC in the CAR assay. These data support previous findings that suggested that M4AChR activation improves both psychotic and cognitive symptoms of schizophrenia and may be an important component of the antipsychotic-like efficacy of atypical neuroleptics (Chan et al, 2008; Perry et al, 2001; Shekhar et al, 2008; Zeng et al, 1997). However, the finding that in the mixed CF-1 120 SvEv background, changes in BuTAC sensitivity only occurred at high doses and that in C57Bl/6 mice BuTAC was right-shifted-but still maintained activitysuggests that the CAR activity of BuTAC is mediated by additional pharmacology. The pattern of results from our studies indicates a gene $\times$ pharmacology interaction: $\mathrm{Bu}-$ TAC was devoid of activity in double $\mathrm{M} 2 / \mathrm{M} 4^{-1-}$ mice and $\mathrm{M} 2^{-1-}$ mice did not show altered sensitivity to BuTAC. However, the sensitivity of $\mathrm{M} 4^{-1-}$ mice to BuTAC was affected, to a degree, by genetic background. The conditioned avoidance responding task is heavily dependent on mesolimbic dopaminergic neurotransmission (Reis et al, 2004); it is possible that different striatal muscarinic AChR expression density patterns exist between C57BL/6 and CF$1 \times 129$ SvEv mice, which may be further amplified by constitutive gene deletions of the M4AChR.

Although it is tempting to conclude that haloperidol differentially affected avoidance responding in $\mathrm{M} 4^{-1-}$ mice relative to $\mathrm{M} 2 / \mathrm{M} 4^{-1-}$ mice, it should be noted that avoidance responding in $\mathrm{M} 4^{-I-}$ on the $\mathrm{C} 57 \mathrm{Bl} / 6$ background differed significantly from the $\mathrm{M} 2^{-1-}$ mice on the C57Bl/6 background, but not from their WT controls. Similarly, M2 ${ }^{-1-}$ mice on the C57Bl/6 background did not differ from WT controls. Thus, the effects of haloperidol on avoidance responding did not differ between $\mathrm{M} 2 / \mathrm{M} 4^{-/-}$ and $\mathrm{M} 4^{-1-}$ mice, confirming that the antipsychotic efficacy of haloperidol is not mediated by M4AChRs. This is consistent with binding and functional activity of haloperidol. Rather, the difference in haloperidol potency between $\mathrm{M} 4^{-1-}$ and $\mathrm{M} 2 / \mathrm{M} 4^{-1-}$ mice may be related to differences in basal dopamine dynamics mediated by background strain, as discussed above (He and Shippenberg, 2000).

Clozapine has been reported to display partial agonist activity at the M2- and M4AChRs; however, the data presented here suggest that its antipsychotic-like efficacy may not be related to its reported partial agonist properties at these receptor subtypes (Michal et al, 1999; Olianas et al, 1999; Zeng et al, 1997). Our in vitro functional selectivity profile for clozapine at the M1-M5AChRs, obtained using the GTP- $\gamma-\left[{ }^{35} \mathrm{~S}\right]$ binding assay, showed only modest M2AChR agonism and did not indicate any agonism at the M4AChR (Table 1). Methodological differences may account for interlab discrepancies in the in vitro pharmacology of clozapine, but the conditioned avoidance data reported here suggest little functional contribution of M2or M4AChR effects of clozapine in this assay. Our results do confirm previous reports that clozapine exhibits greater affinity for M1AChRs than M2- or M4AChRs and displays partial antagonist activity at the M1AChR subtype (Bolden et al, 1992; Table 1). Recently, another group evaluated the role of the M1- and M4AChRs, via the use of M1 ${ }^{-/-}$, $\mathrm{M} 4^{-1-}$, and M1/M4AChR double-knockout mice, on the modulation of prepulse inhibition (PPI) by clozapine (Thomsen et al, 2010). PPI is a measure of sensorimotor gating processes and is reliably found to be disrupted in central nervous system disorders involving attention, such as schizophrenia (Swerdlow et al, 2008). Our findings in the conditioned avoidance responding assay support those of Thomsen et al (2010) in which genetic ablation of M4AChR does not appear to mediate the antipsychotic-like effects of clozapine. Clozapine exhibits a rich pharmacological profile, particularly across monoamine receptors, and the antipsychotic-like effects of clozapine in the conditioned avoidance assay are unlikely related to its activity at M2- or M4AChRs. Our data also suggest that the major clozapine metabolite $N$-desmethylclozapine does not exert significant actions through M2 or M4AChRs; however, our study was not able to evaluate its putative M1AChR agonist activity (Sur et al, 2003). Interestingly, in the Thomsen et al (2010) paper, the authors showed that M4AChR signaling does play a role in mediating the antipsychotic-like effects of the M1-/ M4AChR-preferring agonist xanomeline, which has a similar pharmacological signature to that of BuTAC.

Consistent with an atypical antipsychotic-like profile, BuTAC showed a good dose separation for reducing avoidance responding (ie, efficacy measure) vs propensity for producing escape failures (ie, motor side-effect measure), although escape failures were observed at higher doses in the mice on a mixed CF- $1 \times 129$ SvEv background. Taken together, the therapeutic profile of BuTAC across the studies indicates that efficacy in CAR was not likely confounded by nonselective motor or sedative effects seen with potent dopamine D2 blockers, such as haloperidol. The atypical-like therapeutic profile of BuTAC (and xanomeline from literature reports) suggests that $\mathrm{mAChR}$ agonistmediated antipsychotic medications may be less likely to produce undesirable motor side effects than currently available neuroleptics (Rasmussen et al, 2001; Shannon et al, 2000; Stanhope et al, 2001). However, it was recently reported that M4AChR knockout mice display an attenuated cataleptic response to antipsychotics, suggesting that an M4AChR agonist may induce motor side effects (FinkJensen et al, 2011). Such findings highlight the need for conditional knockout animals, as constitutive genetic modifications may cause some neurodevelopmental alterations that cannot presently be ruled out. M4AChR-positive allosteric modulators have not been reported to cause catalepsy in rodents, but definitive data will await clinical studies with selective tools. This pattern of results suggests that $\mathrm{mAChR}$ agonism preferentially modulates dopamine signaling within mesolimbic (A10) pathways, rather than nigrostriatal (A9) pathways believed to mediate extrapyramidal side effects associated with potent DA D2 blockers.

The neuroanatomical locus by which mAChRs, and M4AChRs in particular, exert influence upon dopaminergic activity is not fully elucidated, but accumulating evidence 
suggests a strong relationship with dopamine D1 receptor function (Ince et al, 1997; Zhang et al, 2002). Specifically, M4 receptor knockout mice show enhanced sensitivity to the stimulating effects of D1 agonism (Gomez et al, 1999b). M4AChR is the predominant muscarinic receptor subtype expressed in the striatum and is localized on cholinergic interneurons and, along with D1 receptors, on GABAergic projection neurons (Bernard et al, 1992; Weiner et al, 1990; Yan et al, 2001). Consistent with these neuroanatomical observations, M4AChR-deficient mice exhibit a significantly reduced ability of the nonselective muscarinic agonist oxotremorine to potentiate potassium-stimulated striatal dopamine release (Zhang et al, 2002). Moreover, selective and conditional genetic deletion of M4AChRs from D1expressing cells in the striatum resulted in a loss of muscarinic agonist-mediated reversal of amphetaminestimulated activity in mice (Dencker et al, 2011). As D1 receptors reside on dendritic spines in key frontal cortical structures and modulate the integrity of cortical networks (Arnsten, 2011), the close neuroanatomical and functional relationship between M4 and D1 receptors would be predicted to affect both cortical and striatal functioning, key substrates that are dysregulated in schizophrenia. Recently, however, it was shown that M4AChRs and D1 receptors do not appear to colocalize in cortical areas (Dencker et al, 2012).

An imbalance between dopaminergic and cholinergic neurotransmitter systems in mesolimbic and frontocortical areas may be involved in the pathophysiology of psychosis and other psychiatric disorders. Accumulating evidence suggests that modulating these systems via mAChRs may be a safe, effective alternative to currently available medications (Ma et al, 2008; Rasmussen et al, 2001; Shekhar et al, 2008). As demonstrated here, BuTAC effectively inhibited conditioned avoidance responding in mice, an animal model predictive of clinical antipsychotic efficacy, without inducing escape failures. The current data also indicate that the antipsychotic-like effects of BuTAC are mediated predominantly, although not exclusively, through M4AChR signaling. The dense localization of M4AChRs in the hippocampus, cerebral cortex, and striatum suggests that this mAChR subtype may be useful as a pharmacological target for the treatment of schizophrenia and other psychiatric disorders (Ma et al, 2008). Recent post-mortem findings suggest that M4AChR dysregulation may translate into the clinic, as a subset of schizophrenic patients were observed to have deficiencies in M4AChR expression (Scarr et al, 2007). In addition to displaying full and partial agonist activity at the M2- and M4AChRs, respectively, BuTAC also acts as a potent partial agonist at the M1AChR (Table 1 and Figure $1 \mathrm{a}, \mathrm{b}$, and $\mathrm{d}$ ). Concomitant with this activity profile, BuTAC also behaves as an antagonist at the M1-, M3-, M4-, and M5AChRs (Table 1 and Figure $1 \mathrm{a}$ and $\mathrm{c}-\mathrm{e}$ ), activities that may also contribute to its behavioral profile. Evaluation of these other mAChR subtypes in the mediation of the antipsychotic-like effects of BuTAC is currently under investigation. The pharmacological profile of BuTAC supports further evaluation of the M4AChR as a drug target for psychotic disorders and may represent an innovative therapeutic approach in the treatment of psychosis with little potential for cognitive impairment or motor side effects.

\section{FUNDING AND DISCLOSURE}

All authors were full-time employees of Eli Lilly at the time the experiments were performed and all studies included in this manuscript have been financially supported by Eli Lilly. The authors declare that, aside from income received from their primary pharmaceutical company employers, no author has received any additional financial support or compensation from any individual or other corporate entity over the past three years for research or professional service.

\section{REFERENCES}

Arnsten AF (2011). Catecholamine influences on dorsolateral prefrontal cortical networks. Biol Psychiatry 69: e89-e99.

Bernard V, Normand E, Bloch B (1992). Phenotypical characterization of the rat striatal neurons expressing muscarinic receptor genes. J Neurosci 12: 3591-3600.

Bolden C, Cusack B, Richelson E (1992). Antagonism by antimuscarinic and neuroleptic compounds at the five cloned human muscarinic cholinergic receptors expressed in Chinese hamster ovary cells. J Pharmacol Exp Ther 260: 576-580.

Bymaster FP, Carter PA, Yamada M, Gomeza J, Wess J, Hamilton $\mathrm{SE}$ et al (2003a). Role of specific muscarinic receptor subtypes in cholinergic parasympathomimetic responses, in vivo phosphoinositide hydrolysis, and pilocarpine-induced seizure activity. Eur J Neurosci 17: 1403-1410.

Bymaster FP, Felder C, Ahmed S, McKinzie D (2002). Muscarinic receptors as a target for drugs treating schizophrenia. Curr Drug Targets CNS Neurol Disord 1: 163-181.

Bymaster FP, McKinzie DL, Felder CC, Wess J (2003b). Use of M1M5 muscarinic receptor knockout mice as novel tools to delineate the physiological roles of the muscarinic cholinergic system. Neurochem Res 28: 437-442.

Bymaster FP, Shannon HE, Rasmussen K, Delapp NW, Mitch CH, Ward JS et al (1998). Unexpected antipsychotic-like activity with the muscarinic receptor ligand (5R,6R)6-(3-propylthio-1,2,5thiadiazol-4-yl)-1-azabicyclo[3.2.1] octane. Eur J Pharmacol 356: 109-119.

Chan WY, McKinzie DL, Bose S, Mitchell SN, Witkin JM, Thompson RC et al (2008). Allosteric modulation of the muscarinic M4 receptor as an approach to treating schizophrenia. Proc Natl Acad Sci USA 105: 10978-10983.

DeLapp NW, McKinzie JH, Sawyer BD, Vandergriff A, Falcone J, McClure D et al (1999). Determination of [35 S]guanosine-5'-O(3-thio)triphosphate binding mediated by cholinergic muscarinic receptors in membranes from Chinese hamster ovary cells and rat striatum using an anti-G protein scintillation proximity assay. J Pharmacol Exp Ther 289: 946-955.

Dencker D, Wortwein G, Weikop P, Jeon J, Thomsen M, Sager TN et al (2011). Involvement of a subpopulation of neuronal M4 muscarinic acetylcholine receptors in the antipsychotic-like effects of the M1/M4 preferring muscarinic receptor agonist xanomeline. J Neurosci 31: 5905-5908.

Dencker D, Weikop P, Sørensen G, Woldbye DPD, Wörtwein G, Wess J et al (2012). An allosteric enhancer of M4 muscarinic acetylcholine receptor function inhibits behavioral and neurochemical effects of cocaine. Psychopharmacology 224: 277-287.

Felder CC, Bymaster FP, Ward J, DeLapp N (2000). Therapeutic opportunities for muscarinic receptors in the central nervous system. J Med Chem 43: 4333-4353.

Feldman RS, Meyer JS, Quenzer LF (1997). Principles of Neuropsychopharmacology. Sinauer Associates: Sunderland, MA. Fink-Jensen A, Schmidt LS, Dencker D, Schülein C, Wess J, Wörtwein G et al (2011). Antipsychotic-induced catalepsy is 
attenuated in mice lacking the M4 muscarinic acetylcholine receptor. Eur J Pharmacol 656: 39-44.

Forster GL, Yeomans JS, Takeuchi J, Blaha CD (2002). M5 muscarinic receptors are required for prolonged accumbal dopamine release after electrical stimulation of the pons in mice. J Neurosci 22: RC190.

Gerber DJ, Sotnikova TD, Gainetdinov RR, Huang SY, Caron MG, Tonegawa S (2001). Hyperactivity elevated dopaminergic transmission and response to amphetamine in M1 muscarinic acetylcholine receptor-deficient mice. Proc Natl Acad Sci USA 98: 15312-15317.

Gomeza J, Shannon H, Kostenis E, Felder C, Zhang L, Brodkin J et al (1999a). Pronounced pharmacologic deficits in M2 muscarinic acetylcholine receptor knockout mice. Proc Natl Acad Sci USA 96: 1692-1697.

Gomeza J, Zhang L, Kostenis E, Felder CC, Bymaster FP, Brodkin J et al (2001). Generation and pharmacological analysis of M-2 and M-4 muscarinic receptor knockout mice. Life Sci 68: 2457-2466.

Gomeza J, Zhang L, Kostenis E, Felder C, Bymaster F, Brodkin J et al (1999b). Enhancement of D1 dopamine receptor-mediated locomotor stimulation in $\mathrm{M}(4)$ muscarinic acetylcholine receptor knockout mice. Proc Natl Acad Sci USA 96: 10483-10488.

He M, Shippenberg TS (2000). Strain differences in basal and cocaine-evoked dopamine dynamics in mouse striatum. J Pharmacol Exp Ther 293: 121-127.

Hersch SM, Gutekunst CA, Rees HD, Heilman CJ, Levey AI (1994). Distribution of m1-m4 muscarinic receptor proteins in the rat striatum: light and electron microscopic immunocytochemistry using subtype-specific antibodies. J Neurosci 14: 3351-3363.

Ince E, Ciliax BJ, Levey AI (1997). Differential expression of D1 and $\mathrm{D} 2$ dopamine and $\mathrm{m} 4$ muscarinic acetylcholine receptor proteins in identified striatonigral neurons. Synapse 27: 357-366.

Jones CK, Eberle EL, Shaw DB, McKinzie DL, Shannon HE (2005). Pharmacologic interactions between the muscarinic cholinergic and dopaminergic systems in the modulation of prepulse inhibition in rats. J Pharmacol Exp Ther 312: 1055-1063.

Kristiansen K (2004). Molecular mechanisms of ligand binding, signaling, and regulation within the superfamily of G-proteincoupled receptors: molecular modeling and mutagenesis approaches to receptor structure and function. Pharmacol Ther 103: $21-80$.

Ma AW, Pawagi AB, Wells JW (2008). Heterooligomers of the muscarinic receptor and $G$ proteins purified from porcine atria. Biochem Biophys Res Commun 374: 128-133.

Michal P, Lysikova M, El-Fakahany EE, Tucek S (1999). Clozapine interaction with the M2 and M4 subtypes of muscarinic receptors. Eur J Pharmacol 376: 119-125.

Olianas MC, Maullu C, Onali P (1999). Mixed agonist-antagonist properties of clozapine at different human cloned muscarinic receptor subtypes expressed in Chinese hamster ovary cells. Neuropsychopharmacology 20: 263-270.

Perry KW, Nisenbaum LK, George CA, Shannon HE, Felder CC, Bymaster FP (2001). The muscarinic agonist xanomeline increases monoamine release and immediate early gene expression in the rat prefrontal cortex. Biol Psychiatry 49: 716-725.

Rasmussen T, Fink-Jensen A, Sauerberg P, Swedberg MD, Thomsen C, Sheardown MJ et al (2001). The muscarinic receptor agonist BuTAC, a novel potential antipsychotic, does not impair learning and memory in mouse passive avoidance. Schizophr Res 49: 193-201.

Reis FL, Masson S, de Oliveira AR, Brandao ML (2004). Dopaminergic mechanisms in the conditioned and unconditioned fear as assessed by the two-way avoidance and light switch-off tests. Pharmacol Biochem Behav 79: 359-365.
Sauerberg P, Jeppersen L, Olesen PH, Rasmussen T, Swedberg MDR, Sheardown MJ et al (1998). Muscarinic agonists with antipsychotic-like activity: Structure-activity relationships of 1,2,5-thiadiazole analogues with functional dopamine antagonist activity. J Med Chem 22: 1998.

Scarr E, Sundram S, Keriakous D, Dean B (2007). Altered hippocampal muscarinic M4, but not M1, receptor expression from subjects with schizophrenia. Biol Psychiatry 61: 1161-1170.

Schmidt LS, Miller AD, Lester DB, Bay-Richter C, Schulein C, Frikke-Schmidt $\mathrm{H}$ et al (2010). Increased amphetamine-induced locomotor activity, sensitization, and accumbal dopamine release in M5 muscarinic receptor knockout mice. Psychopharmacology (Berl) 207: 547-558.

Shannon HE, Bymaster FP,DO, Calligaro DO, DeLapp NW, Jones C, Perry K et al (1999). Antipsychotic-like pharmacologic profile of the muscarinic agonist BuTAC. Schizophr Res 36: 314.

Shannon HE, Rasmussen K, Bymaster FP, Hart JC, Peters SC, Swedberg MD et al (2000). Xanomeline, an $\mathrm{M}(1) / \mathrm{M}(4)$ preferring muscarinic cholinergic receptor agonist, produces antipsychoticlike activity in rats and mice. Schizophr Res 42: 249-259.

Shekhar A, Potter WZ, Lightfoot J, Lienemann J, Dube S, Mallinckrodt C et al (2008). Selective muscarinic receptor agonist xanomeline as a novel treatment approach for schizophrenia. Am J Psychiatry 165: 1033-1039.

Stanhope KJ, Mirza NR, Bickerdike MJ, Bright JL, Harrington NR, Hesselink MB et al (2001). The muscarinic receptor agonist xanomeline has an antipsychotic-like profile in the rat. $J$ Pharmacol Exper Ther 299: 782-792.

Steidl S, Miller AD, Blaha CD, Yeomans JS (2011). M5 muscarinic receptors mediate striatal dopamine activation by ventral tegmental morphine and pedunculopontine stimulation in mice. PLoS One 6: e27538.

Sur C, Mallorga PJ, Wittmann M, Jacobson MA, Pascarella D, Williams JB et al (2003). N-desmethylclozapine, an allosteric agonist at muscarinic 1 receptor potentiates N-methyl-Daspartate receptor activity. Proc Natl Acad Sci USA 100: 13674-13679.

Swerdlow NR, Weber M, Qu Y, Light GA, Braff DL (2008). Realistic expectations of prepulse inhibition in translational models for schizophrenia research. Psychopharmacology 199: 331-388.

Thomsen M, Wess J, Fulton B, Fink-Jensen A, Caine S (2010). Modulation of prepulse inhibition through both through both $\mathrm{M}(1)$ and $\mathrm{M}(4)$ muscarinic receptors in mice. Psychopharmacology 208: 401-416.

Wadenberg ML, Soliman A, VanderSpek SC, Kapur S (2001). Dopamine $\mathrm{D}(2)$ receptor occupancy is a common mechanism underlying animal models of antipsychotics and their clinical effects. Neuropsychopharmacology 25: 633-641.

Weiner DM, Levey AI, Brann MR (1990). Expression of muscarinic acetylcholine and dopamine receptor mRNAs in rat basal ganglia. Proc Natl Acad Sci USA 87: 7050-7054.

Woolf NJ (1991). Cholinergic systems in mammalian brain and spinal cord. Prog Neurobiol 37: 475-524.

Yan Z, Flores-Hernandes J, Surmeier DJ (2001). Coordinated expression of muscarinic receptor messenger RNAs in striatal medium spiny neurons. Neuroscience 103: 1017-1024.

Zeng XP, Le F, Richelson E (1997). Muscarinic m4 receptor activation by some atypical antipsychotic drugs. Eur J Pharmacol 321: 349-354.

Zhang W, Yamada M, Gomeza J, Basile AS, Wess J (2002). Multiple muscarinic acetylcholine receptor subtypes modulate striatal dopamine release, as studied with M1-M5 muscarinic receptor knock-out mice. J Neurosci 22: 6347-6352. 